\title{
Embodied carbon dioxide of network assets in a decarbonised electricity grid
}

Article

Accepted Version

Creative Commons: Attribution-Noncommercial-No Derivative Works 4.0

Daniels, L., Coker, P. and Potter, B. (2016) Embodied carbon dioxide of network assets in a decarbonised electricity grid. Applied Energy, 180. 142 - 154. ISSN 0306-2619 doi: https://doi.org/10.1016/j.apenergy.2016.07.044 Available at https://centaur.reading.ac.uk/66547/

It is advisable to refer to the publisher's version if you intend to cite from the work. See Guidance on citing.

Published version at: http://www.sciencedirect.com/science/article/pii/S0306261916309849

To link to this article DOI: http://dx.doi.org/10.1016/j.apenergy.2016.07.044

Publisher: Elsevier

All outputs in CentAUR are protected by Intellectual Property Rights law, including copyright law. Copyright and IPR is retained by the creators or other copyright holders. Terms and conditions for use of this material are defined in the End User Agreement.

\section{www.reading.ac.uk/centaur}

\section{CentAUR}

Central Archive at the University of Reading

Reading's research outputs online 


\title{
Embodied Carbon Dioxide of Network Assets in a Decarbonised Electricity Grid
}

\author{
Laura Daniels ${ }^{\mathrm{a}}$, Phil Coker $^{\mathrm{b}}$, Ben Potter $^{\mathrm{c}}$ \\ ${ }^{a}$ Technologies for Sustainable Built Environments (TSBE) Centre, University of Reading, UK \\ ${ }^{b}$ School of Built Environment, University of Reading, UK \\ ${ }^{c}$ Energy Research Lab, School of Systems Engineering, University of Reading, UK
}

\begin{abstract}
Calculating carbon dioxide $\left(\mathrm{CO}_{2}\right)$ emissions associated with electricity is a key component in the field of Life Cycle Assessment (LCA), but is often cited as challenging due to the complex nature of electricity systems despite its importance to the outcome. While calculating the operational $\mathrm{CO}_{2}$ emissions associated with electricity generation is an active research field, the embodied $\mathrm{CO}_{2}$ emissions, typically referred to as embodied carbon, of network assets has far less representation in the literature. This paper focuses on the $\mathrm{CO}_{2}$ emissions aspect of LCA to calculate the embodied $\mathrm{CO}_{2}$ of network assets in relation to the operational grid $\mathrm{CO}_{2}$ over time. Several functional units are defined: $\mathrm{CO}_{2}$ per operational year, $\mathrm{CO}_{2}$ per asset cost, $\mathrm{CO}_{2}$ per functional unit of electricity $(\mathrm{kWh})$ and the relationship between embodied emissions and operational emissions in an electricity system over time. Hybrid functional units are then applied in order to better attribute the embodied carbon to the network functions. The hybrid functional units involve network asset lifetime and the issue of temporal horizons. Several suitable horizons are suggested and the comparison of results highlight the importance of the timeframe on results. The relationship between temporal horizons and environmental discounting is discussed and recommendations are made on the appropriate level of discounting depending on the temporal horizon and the purpose of the LCA. The paper uses data from the Great Britain electricity system where planned investment in network assets is $£ 12$ bn at distribution level (Dx) and £16.4bn at transmission level (Tx) over the next eight years. By using GB network data for embodied carbon, demand and asset data, as well as data from the decarbonisation of electricity generation, indicative results are provided into the way in which embodied carbon impacts could change over time, showing that by 2035 , the embodied carbon of the transmission network could contribute almost $25 \%$ of total emissions associated with electricity. On a regional basis, DNO level network assets could reach anywhere between $40 \%$ and $130 \%$. This network data is also used to show that new network investment could account for up to $6.5 \%$ of DNO level network embodied carbon when front loaded during the RIIO-ED1 period.
\end{abstract}

Keywords: LCA, electricity, decarbonisation, embodied carbon dioxide, temporal horizons, environmental discounting

Email address: b.a.potter@.reading.ac.uk (Ben Potter) 


\section{Introduction}

The electricity sector is instrumental in the move to a low carbon economy. Calculating the carbon dioxide $\left(\mathrm{CO}_{2}\right)$ emissions associated with electricity generation and transmission is an essential component of designing policy to meet global emissions reduction targets. The calculation of the $\mathrm{CO}_{2}$ emissions associated with the operation of the generation-side of electricity networks (operational carbon) is an active research area. Life Cycle Assessments (LCA) of the operational and embodied emissions of different generation technologies are well established e.g. [1, 2] and used by policy makers to compare options for the future low carbon electricity supply.

Electricity consumption is noted as a difficult component in many product LCAs e.g. [3, 4] despite its importance to the outcome. Due to the complex nature of electricity systems, whose operations are time dependent - both on a daily and annual scale, it is difficult to associate the direct impact of electricity consumption at a particular site. In this area of LCA methodology, it is important that the whole electricity network is considered, not just the operational aspect of electricity generation, but also the embodied emissions associated with the electricity network assets.

This impact of the embodied $\mathrm{CO}_{2}$ emissions (embodied carbon) is absent from much of the literature, which focuses on the operational $\mathrm{CO}_{2}$ of electricity generation technologies. The embodied $\mathrm{CO}_{2}$ impacts associated with the electricity network are due to the materials and the construction and ongoing maintenance activities associated with network assets such as pylons, transformers and cables. The embodied $\mathrm{CO}_{2}$ of network assets are discussed in a wider set of smart grid literature as a consequence of network investment deferral due to the increase of DG and DSM. While several studies suggest that embodied $\mathrm{CO}_{2}$ savings due to reduced or deferred network investment is likely e.g. [5-7], none attempt to quantify this saving. This paper builds on work from an initial LCA of the GB transmission network [8] and previous studies by the authors [9, 10] which introduced the concept of proxies to calculate embodied $\mathrm{CO}_{2}$ of network assets. Now, these proxies are applied and the embodied $\mathrm{CO}_{2}$ of network assets is placed in the context of its proportion of total grid $\mathrm{CO}_{2}$ over time, considering changing demand and carbon intensity.

As the electricity supply is decarbonised, the operational grid emissions are reduced thus increasing the importance of embodied $\mathrm{CO}_{2}$ of the electricity network. This growing importance highlights the need for methods to evaluate the embodied $\mathrm{CO}_{2}$ of electricity networks. Accounting for this complex measurement depends on the assumptions that are made about what the electricity system may look like in the future. Predictions about electricity systems can extend to 50 years but some network assets may have expected lifetimes of 80 years [11], making it difficult to account for the embodied $\mathrm{CO}_{2}$ associated with the asset across its whole lifetime. In addition to this disparity in time considerations, the electricity network is a constantly changing and evolving system - both from and operational and asset perspective. The transition to a low carbon electricity supply will not just see changes in generation assets but also large changes in the electricity network. In the GB network, this network change could require 16.4bn GBP of investment in the transmission network alone [12]. This level of investment will see major changes in the assets - with old assets being retired and new assets, with embodied $\mathrm{CO}_{2}$ impacts, being built.

In order to account for these complexities and to discuss how electricity network assets should be most effectively 
accounted for in LCA, this paper focuses on the $\mathrm{CO}_{2}$ emissions aspect of LCA calculations. While LCAs often include a range of other greenhouse gas emissions, the paper uses $\mathrm{CO}_{2}$ due to a lack of data for the electricity network for other gases, particularly the network assets. The paper calculates the changing ratio of operational generation grid $\mathrm{CO}_{2}$ to embodied network grid $\mathrm{CO}_{2}$ over time. The paper considers generation, transmission and distribution and how the composition of each of these aspects may change over time. Using the GB network investment and demand data at both transmission and distribution level as a case study, the paper highlights the importance of this relationship between embodied and operational $\mathrm{CO}_{2}$ emissions and how this relationship may change during the transition to a low carbon electricity supply. By using real data from the GB network for asset lifetimes and predicted demand data in place of static assumptions, results from a previous study are improved upon [8]. This paper shows the growing importance of considering embodied $\mathrm{CO}_{2}$ of network assets in policy decisions. The distinct lack of focus on the embodied $\mathrm{CO}_{2}$ impact of electricity networks must change in order for full understanding of the environmental impacts of electricity network changes in the coming years.

\section{Life Cycle Assessment for Electricity Networks}

The importance of fully understanding and assessing the impacts of future electricity systems is clear. The increase in the use of LCA and the importance placed on embodied $\mathrm{CO}_{2}$ at policy level shows the importance in understanding total impact of a wide range of products and services. As global electricity systems are decarbonised, it will be increasingly important to take account of the embodied $\mathrm{CO}_{2}$ of electricity network assets when assessing impacts of electricity generation. The ratio of operational to embodied $\mathrm{CO}_{2}$ is commonly used when considering the environmental impact of construction [13] and has become an important measure in the construction of non domestic buildings. This whole system view of a building should be applied to other systems, including electricity networks.

As such an important aspect of products and services globally, the use of LCA to determine environmental impacts of electricity is an active research area. There are international standards for determining the $\mathrm{CO}_{2}$ associated with an electricity network [14, 15] but often these focus on generation assets and do not account for emissions associated with network assets. LCA of electricity generation technologies [16, 17] and national audits of generation technologies in a given electricity network [1, 2, 18] are well established which account for the embodied $\mathrm{CO}_{2}$ associated with generation assets but not network assets, such as pylons and cables which are the primary focus of this work.

There are several challenges in LCA methodology which are applicable to electricity systems. The two most notable are the challenges of dealing with time, and defining a suitable functional unit.

Traditionally in LCA, an inventory of the emissions that occur during a product or service lifetime is produced and this emissions is aggregated to provide a singular 'emission' associated with the product or service [19]. This approach fails to take into consideration the different times over which the emissions take place - meaning an emission contribution made today or in 200 years are considered equally [20]. A time horizon is the length of time that an LCA considers. For electricity networks, there are differing timescales considered - a planning framework may be 8-10 
years, an electricity generation asset may have a lifetime of 25 years and a network asset may have a lifetime of 80 years. In addition to this, the electricity network has no expected end of life stage as an entire system - and is instead made of many components, each with different lifetimes. There are some studies which aim to determine the temporal aspect of the electricity system, but more commonly this is addressed using the operational carbon intensity of differing electricity generation technologies - giving a carbon intensity profile over the course of a day for a given network [3, 21] The embodied $\mathrm{CO}_{2}$ aspect of long term network asset decisions is absent from these studies and would need including to give a full picture of the $\mathrm{CO}_{2}$ emissions associated with grid electricity.

A functional unit determines how $\mathrm{CO}_{2}$ emissions are attributed to a certain product or service in LCA methodology. In some cases, the functional unit is clear, which is often the case with products. For example, the functional unit of crisp manufacture would be the number of bags of crisps made. However, for services, systems or processes the functional unit can be more difficult to define - because there can be several functions or the function may be ambiguous. Defining suitable functional units is a well established issue in LCA methodology and has even been cited as the most severe and unaddressed problem in the field of LCA [22].

A recent LCA study of the GB Transmission Network [8] gave detailed analyses of the materials and construction associated with transmission level network assets. Using the results from this study and improving on assumptions used for the application of the results is important in order to continue to improve the understanding of the impact of electricity network assets to total grid $\mathrm{CO}_{2}$.

\section{Approach}

In order to explore the comparison between grid operational $\mathrm{CO}_{2}$ emissions to embodied $\mathrm{CO}_{2}$ emissions, a number of methods are assessed. A range of functional units are defined and their suitability discussed. Hybrid functional units are also suggested due to the complex nature of electricity networks. In order to account for time, network asset lifetime data is used and the issue of temporal horizons is discussed. Several temporal horizons are suggested and the results for each show the importance of the temporal horizon selection. In order to account for the long network asset lifetimes, environmental discounting is explored and Replacement Values of assets are calculated. The paper uses a cradle to grave approach, covering the four main stages of the product life cycle, including decommissioning.

In order to build on the previous study, this paper will calculate the metric of the ratio of operational $\mathrm{CO}_{2}$ to embodied $\mathrm{CO}_{2}$ in a number of stages. Initially, network asset composition, asset lifetime and demand are kept static while operational grid $\mathrm{CO}_{2}$ is updated in line with the predicted carbon intensity of the future electricity generation mix for the UK.

\section{GB Data and LCA Methodological Challenges}

GB system data is used to provide context. The GB network and market structure operates separately to the Irish electricity network and market, which is why GB is discussed, not UK. The high voltage electricity network is 
operated by the System Operator (SO), which in the GB network is National Grid Electricity Transmission plc. The low voltage network is operated by 14 licensed DNOs each responsible for a regional distribution area, as shown in Table 1 . The SO and DNOs are natural monopolies regulated by the Office for Gas and Electricity Markets (Ofgem). Asset, investment and demand data from the GB SO and DNOs is used as a case study. Initially functional units are defined to be used across a DNO region and at SO level, but the use of hybrid functional units is then discussed as a means for further analysis.

Table 1: Distribution Network Operators in Great Britain

\begin{tabular}{ll}
\hline Region & DNO Name \\
\hline 10 & Eastern Power Networks \\
11 & Western Power -East Midlands \\
12 & London Power Networks \\
13 & Scottish Power Manweb \\
14 & Western Power - West Midlands \\
15 & Northern Power Grid (North East) \\
16 & Electricity North West \\
17 & Scottish Hydro \\
18 & Scottish Power Distribution \\
19 & South Eastern Power Networks \\
20 & Southern Electric Power Distribution \\
21 & Western Power - South Wales \\
22 & Western Power - South West \\
23 & Northern Power Grid (Yorkshire) \\
\hline
\end{tabular}

\subsection{Embodied $\mathrm{CO}_{2}$ of Current Network Assets}

Embodied $\mathrm{CO}_{2}$ data is taken from a previous study [8]; total $\mathrm{CO}_{2}$ associated with two major asset types, overhead lines (OHL) and underground cables (UGC) is used as shown in Table 1a. An average for each major asset type is calculated based on this study and shown in Table $1 \mathrm{~b}$ These calculated average carbon intensities have been used to calculate the embodied emissions associated with the current DNO network assets as shown in Figure 2 [9, 10], by using Equation 1, where embodied carbon intensity factors for the Transmission Network assets are applied to the asset lengths of each asset within each DNO region. Asset data is taken from planning documents published by the DNOs [23-36] and shown in Table 2 This asset data shows the regional variations in the make up of the network. DNO 12, for example, is London where no OHL is permitted. 
Table 2: GB DNO Asset Data

DNO OHL UGC

\begin{tabular}{lll} 
& $(\mathrm{km})$ & $(\mathrm{km})$ \\
\hline 10 & 34,000 & 62,000 \\
11 & 22,000 & 50,000 \\
12 & 0 & 36,000 \\
13 & 18,286 & 29,714 \\
14 & 24,000 & 40,000 \\
15 & 14,800 & 25,800 \\
16 & 13,000 & 44,000 \\
17 & 16,251 & 31,497 \\
18 & 21,714 & 35,286 \\
19 & 12,000 & 40,000 \\
20 & 27,173 & 49,626 \\
21 & 18,000 & 17,000 \\
22 & 28,000 & 22,000 \\
23 & 13,400 & 39,800 \\
\hline
\end{tabular}


(a) GB Transmission Network Embodied $\mathrm{CO}_{2}$ and Asset Length [8]

\begin{tabular}{lll}
\hline Asset & $\mathrm{tCO}_{2}$ & $\begin{array}{l}\text { TSO length } \\
(\mathrm{km})\end{array}$ \\
\hline OHL & $2,600,000$ & 22,670 \\
UGC & 700,000 & 887 \\
\hline
\end{tabular}

(b) Average Embodied Carbon Intensities of GB Transmission Network Assets

\begin{tabular}{ll}
\hline Asset & $\begin{array}{l}\text { Carbon Intensity } \\
\mathrm{tCO}_{2} / \mathrm{km}\end{array}$ \\
\hline OHL & 114.69 \\
UGC & 789.18 \\
\hline
\end{tabular}

Figure 1: GB Network Asset Total $\mathrm{CO}_{2}$ and Derived Average Carbon Intensities

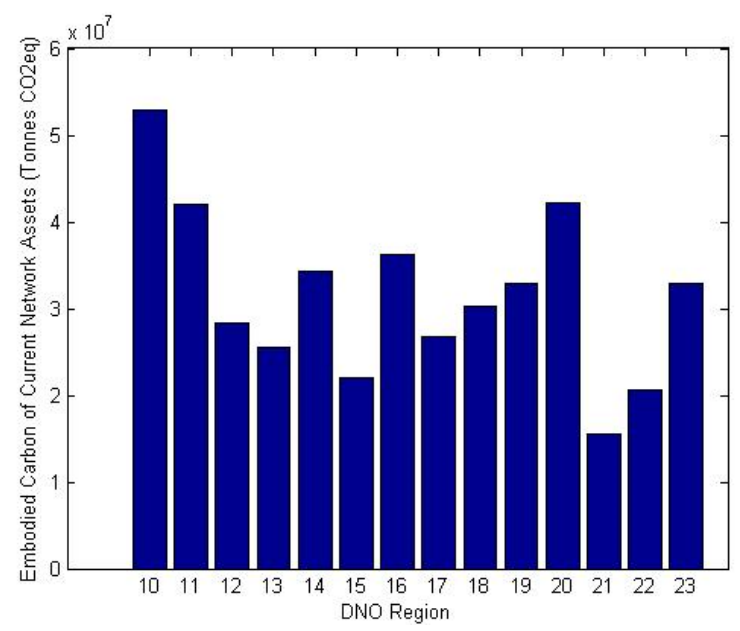

Figure 2: Estimated Embodied $\mathrm{CO}_{2}$ Emissions of Current Distribution Network Assets

Although at TNO level, asset data for transformers and substations is available, they are not included because of the difficulty in comparing non-similar units and in order to keep the method consistent when applying DNO level data. OHL and UGC are considered internally similar - despite different voltage levels having different material and construction requirements. However, given the scope of this paper, an average for each cable type is used. Figure 2 shows the difference in embodied emissions across the 14 DNO regions in the GB network. Regions differ due to their make up and ratio of UGC to OHL as well as their size and population density.

$$
E C_{D N O}=L_{O H L D x} O H L_{C_{2}}+L_{U G C D x} U G C_{C_{2}}
$$

\subsection{Selecting the Functional Unit}

The definition of a suitable functional unit is key in the success of LCA. There are five functional units assessed in this paper as shown in Table 3 , accounting for time, cost, length, capacity and delivered electricity. 
Although it is common for LCA assessment that consider electricity generation technologies or systems to use $(\mathrm{kg} / \mathrm{kWh})$ as the functional unit [16, 37], it must be considered that there can be other functions to the electricity network. Meeting peak demand is an essential role of the electricity network, which may mean higher capacity network assets are required - meaning the capacity should be related to the capacity, measured in $(\mathrm{kg} / \mathrm{kW})$. In some regions, delivering electricity to rural, remote customers may be a function of some aspects of the network - meaning that the length of the network assets will increase perhaps disproportionately to the increase in demand. In reality, many systems or products will have multiple functions. In order to explore the impact of the chosen functional unit on calculations of embodied $\mathrm{CO}_{2}$, it is important to consider a number of functional units. The functional unit chosen may also depend on the stage at which the LCA is carried out and by which stakeholder. It would be reasonable, for example, for a manufacturer of network cable to define their functional unit as unit length of cable - making embodied $\mathrm{CO}_{2}$ defined as $\mathrm{CO}_{2}$ per $\mathrm{km}$.

Table 3: A Selection of Possible Functional Units for Electricity Network Assets

\begin{tabular}{ll}
\hline Functional Unit Description & Units \\
\hline Carbon Dioxide per Year & $(\mathrm{kg} / \mathrm{yr})$ \\
Carbon Dioxide per Unit Length & $(\mathrm{kg} / \mathrm{km})$ \\
Carbon Dioxide per Unit Cost & $(\mathrm{kg} / £)$ \\
Carbon Dioxide per Unit Electricity Delivered & $(\mathrm{kg} / \mathrm{kWh})$ \\
Carbon Dioxide per Capacity & $(\mathrm{kg} / \mathrm{kW})$ \\
\hline
\end{tabular}

In order to calculate the embodied $\mathrm{CO}_{2}$ values associated with each functional unit, a range of data available from the DNOs and SO are used. The metric for the functional unit of unit length $(\mathrm{km})$ has already been used and is shown in Table $1 \mathrm{~b}$. This functional unit defines the materials and construction aspect of network asset embodied $\mathrm{CO}_{2}$. Before an asset is commissioned and becomes operational, this functional unit represents the materials and construction methods and this is an important component to consider - as any improvements in construction methodology or material efficiency would be clear in the change of this metric.

The functional unit of time is inherently linked to product lifetimes and for electricity network assets, expected asset lifetime data has a large range. Distribution level asset lifetime data is shown in Table 4 , as published by the DNOs. The asset lifetime data highlights the issue of time - asset data is incomplete and the range of lifetimes is high. DNO 20, for example, provide a range between 10 and 80 years for one asset type. Table 4 shows an average across all DNO data, which indicates that UGC are expected to last longer than OHL. As UGC have a much higher embodied 
carbon intensity than OHL, shown in Figure 8, this increased expected lifetime can be reflected in calculations using time in the functional unit. This average for OHL and UGC is useful for initial comparison but further calculations are carried out by DNO region using the DNO specific estimates provided. Where a range is given, the average of this range is used.

Table 4: Estimated Asset Lifetimes for each GB DNO Region [38, 51]

\begin{tabular}{|c|c|c|c|c|}
\hline & Asset & Lifetime & (yrs) & \\
\hline DNO & OHL & UGC & Meters & $\begin{array}{l}\text { Other Plant } \\
\text { /Machinery }\end{array}$ \\
\hline 10 & $45-60$ & $45-60$ & & $20-60$ \\
\hline 11 & 45 & 70 & 10 & $45-55$ \\
\hline 12 & $45-60$ & $45-60$ & & $20-60$ \\
\hline 13 & 40 & 40 & $2-10$ & $3-25$ \\
\hline 14 & 45 & 70 & 10 & $45-55$ \\
\hline 15 & 45 & 56 & 4 & 60 \\
\hline 16 & 80 & 80 & 5 & $30-60$ \\
\hline 17 & $10-80$ & $10-80$ & & 60 \\
\hline 18 & 40 & 40 & $2-10$ & $3-25$ \\
\hline 19 & $45-60$ & $45-60$ & & $20-60$ \\
\hline 20 & $10-80$ & $10-80$ & & 60 \\
\hline 21 & 45 & 70 & 10 & $45-55$ \\
\hline 22 & 45 & 70 & 10 & $45-55$ \\
\hline 23 & 45 & 45 & $4-5$ & 60 \\
\hline Ave & 55 & 62 & & 52.5 \\
\hline
\end{tabular}

Calculating embodied carbon attributed to units of electricity delivered relies on the choices made about the demand. If historic data is used, the embodied carbon associated with a new asset is being attributed according to previous asset usage. In cases where old assets are replaced on a 'like for like' basis, this may be acceptable. However, network assets may be upgraded, due to higher demands predicted during the actual lifetime of the asset. To calculate the embodied carbon associated with each $\mathrm{kWh}$ electricity delivered, historic demand data is taken from the Directory of UK Energy Statistics, which includes the GB demand data [52] and predicted demand data is taken from UK Government predictions [53], which includes demand data for GB. It can be seen from the historic electricity demand, shown in Figure 3 that demand has grown significantly in the last 50 years, meaning that assumptions about future electricity demand is vital when calculating the embodied $\mathrm{CO}_{2}$ associated with network assets. If, in 1970, a 
calculation were to be made for a new network asset over a given lifetime, assuming that the demand were to remain static would have significantly underestimated the electricity delivered by that network asset in the GB network, for example.

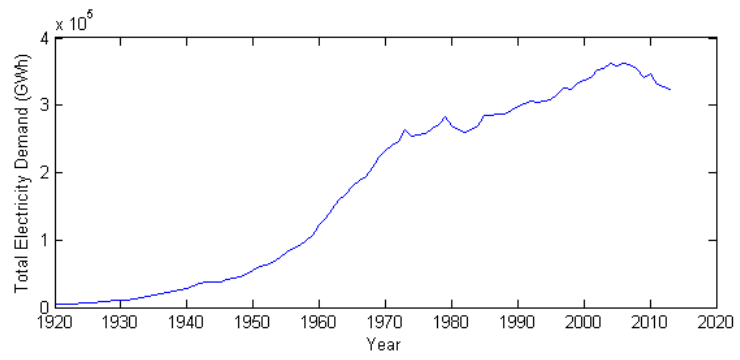

Figure 3: Historical Electricity Demand in the GB Network

Network assets are built to meet peak demand (MW) as well as total electricity delivered (kWh) and for DNO's this capability is vital. Peak demand data is publicly available and 2013 data is shown in Table 4a by GB DNO region. Data from Figure 2 is applied to this peak demand data as shown in Equation 2 taking a ratio of total embodied $\mathrm{CO}_{2}$ in a DNO region to the regions peak demand in a given year.

$$
E C_{\text {Demand }}=\frac{E C_{D N O}}{P D_{D x}}
$$

Whilst cost is not a natural functional unit, there is an inherent relationship between embodied $\mathrm{CO}_{2}$ of network assets and their cost. The SO is subject to a Price Control Review and asset investment data is provided by Ofgem. The allowable OHL Investment per unit is given in the most recent review and shown in Table 5a for transmission network assets and Table $5 \mathrm{~b}$ for distribution level assets [54, 55].

In order to calculate the embodied $\mathrm{CO}_{2}$ per financial investment for the DNO regions, data from Table $1 \mathrm{~b}$ is required. For the current DNO networks, previous work has determined proxies for calculating the embodied $\mathrm{CO}_{2}$ associated with network investment at DNO level [9, 10]. There are several challenges in calculating $\mathrm{CO}_{2}$ emissions associated with network investment spend relating to the breakdown of the spend. The previous study develops proxies based on several methods but for the purpose of this paper, proxies for each network asset type are shown in Table 5 . Calculating the embodied $\mathrm{CO}_{2}$ associated with network investment spend is particularly useful for DNOs but other functional units serve policy makers and regulators better and cost is therefore not used further in this paper.

Selecting an appropriate functional unit can determine the success of an LCA and for complex systems, the selection of a singular functional unit becomes more and more challenging. Inherently, a functional unit should account for the lifetime of network assets, although this is not the primary function for an electricity network asset. It is therefore inappropriate to use a singular functional unit when considering the embodied $\mathrm{CO}_{2}$ associated with electricity network assets. 
(a) DNO Network Asset Embodied $\mathrm{CO}_{2}$ as determined by a Capacity Based Functional Unit

\begin{tabular}{lll}
\hline DNO & $\begin{array}{l}\text { Peak Demand } \\
2013(\mathrm{MW})\end{array}$ & $\begin{array}{l}\text { Embodied } \mathrm{CO}_{2} \\
(\mathrm{t} / \mathrm{MW})\end{array}$ \\
\hline 10 & 6,966 & 7,584 \\
11 & 5,292 & 7,933 \\
12 & 5,417 & 5,245 \\
13 & 3,674 & 6,954 \\
14 & 4,792 & 7,162 \\
15 & 2,800 & 7,878 \\
16 & 3,400 & 10,651 \\
17 & 1,592 & 16,784 \\
18 & 4,718 & 6,430 \\
19 & 4,090 & 8,055 \\
20 & 6,323 & 6,687 \\
21 & 2,118 & 7,309 \\
22 & 2,855 & 7,206 \\
23 & 4,200 & 7,844 \\
Total & 58,236 & 7,601 \\
\hline
\end{tabular}

(b) DNO Network Asset Embodied $\mathrm{CO}_{2}$ as determined by a Capacity Based Functional Unit in 2023

\begin{tabular}{lll}
\hline DNO & $\begin{array}{l}\text { Peak Demand } \\
2023(\mathrm{MW})\end{array}$ & $\begin{array}{l}\text { Embodied } \mathrm{CO}_{2} \\
(\mathrm{t} / \mathrm{MW})\end{array}$ \\
\hline 10 & 7,524 & 7,021 \\
11 & 5,722 & 7,337 \\
12 & 6,151 & 4,619 \\
13 & 4,012 & 6,368 \\
14 & 5,029 & 6,824 \\
15 & & \\
16 & 3,637 & 9,956 \\
17 & & \\
18 & 5,270 & 5,757 \\
19 & 4,303 & 7,656 \\
20 & & \\
21 & 2,237 & 6,920 \\
22 & 3,148 & 6,535 \\
23 & & \\
Total & 58,236 & 7,601 \\
\hline
\end{tabular}

Figure 4: Embodied $\mathrm{CO}_{2}$ when considering Peak Demand as a Functional Unit based on GB Demand Data for 2013 and Predicted Peak Demand Data for 2023

(a) Allowable Costs per Unit of Transmission Network Asset in the GB market

\begin{tabular}{lll}
\hline Asset type & Unit & Cost per Unit \\
\hline Overhead Line & $\mathrm{km}$ & $£ 1,200,000[54]$ \\
Underground Cable & $\mathrm{km}$ & $£ 16,400,000[54]$ \\
\hline
\end{tabular}

(b) Allowable Investment per Unit Distribution Network Assets in the GB market

\begin{tabular}{lcc}
\hline Asset type & Unit & Cost per Unit \\
\hline Low Voltage & & \\
Distribution Main UGC & $\mathrm{km}$ & $£ 98,400$ \\
Low Voltage & & \\
Distribution OHL Rebuild & $\mathrm{km}$ & $£ 28,400$ \\
\hline
\end{tabular}

Figure 5: Allowable Costs per Unit of Network Asset for the GB Transmission and Distribution Networks 
Table 5: Distribution Asset Embodied $\mathrm{CO}_{2}$ as determined by a Cost Based Functional Unit

\begin{tabular}{ll}
\hline Asset Type & $\begin{array}{l}\text { Embodied } \mathrm{CO}_{2} \\
(\mathrm{~kg} / \mathfrak{£})\end{array}$ \\
\hline Low Voltage Main UGC & 4.04 \\
Low Voltage Main OHL Rebuild & 8.02 \\
Distribution Network & \\
\hline
\end{tabular}

\subsection{Hybrid Functional Units}

Calculations so far allow for comparison of total network assets between DNO regions. In order to make further comparisons between future network investment strategies, or to assess network assets on a smaller scale, hybrid functional units must be used. It has been shown that several factors should be considered when analysing the embodied $\mathrm{CO}_{2}$ on assets - the lifetime, the capacity, length and electricity delivered are all key characteristics of a network asset. In some cases, it can already be seen that hybrid functional units are necessary - because in order to estimate the kWh of electricity delivered by a network asset, the expected lifetime of the network asset needs to be known.

A hybrid unit of $\mathrm{kg} / \mathrm{km} / \mathrm{year}$ is calculated for each DNO region and shown in Table 6a This calculation includes network asset lifetime inherently and therefore begins to address the issue of temporal horizons in LCA calculations. Looking towards the electricity delivered, a hybrid functional unit of $\mathrm{kg} / \mathrm{kWh} / \mathrm{km}$ as shown in Table $6 \mathrm{~b}$ highlights the efficiency in length of the network to units of electricity delivered. This ratio will differ between regions due to the population density, demand profile and geographic considerations. Similarly, a unit of $\mathrm{kg} / \mathrm{kW} / \mathrm{km}$ also shown in Table 6 will differ between regions due to the same considerations. For a DNO, consideration of capacity within a hybrid functional unit is important as often new assets are required in order to meet increases in peak demand. For this reason, looking at capacity and time with a hybrid functional unit of $\mathrm{kg} / \mathrm{kW} / \mathrm{year}$, shown in both Table $4 \mathrm{a}$ and Table $4 \mathrm{~b}$ allow for an understanding of the quantity of embodied $\mathrm{CO}_{2}$ is required to meet peak demand in terms of network assets becomes over time.

For most purposes, a hybrid functional unit of $\mathrm{kg} / \mathrm{kWh} / \mathrm{year}$ is suitable. For many purposes, the unit of electricity delivered is still the primary function of the electricity network and when comparing embodied to operational $\mathrm{CO}_{2}$, this unit allows for direct comparison. In practice a hybrid functional unit for electricity network assets has many components. For this paper, a hybrid functional unit of $\mathrm{kg} / \mathrm{kWh} / \mathrm{year}$ is used in order to compare with previous studies in this field, with the aspect of time being accounted for through asset lifetime. However, it should be noted that some of the above hybrid functional units may have their place for DNOs to calculate their total embodied $\mathrm{CO}_{2}$ associated with length and capacity of network assets. 
(a) DNO Network Asset Embodied $\mathrm{CO}_{2}$ as determined by a Time Based Functional Unit

\begin{tabular}{|c|c|c|}
\hline & $\begin{array}{l}\text { Embodied } \\
(\mathrm{kg} / \mathrm{km} / \mathrm{yr})\end{array}$ & $\mathrm{CO}_{2}$ \\
\hline DNO & $\mathrm{OHL}$ & UGC \\
\hline 10 & 2.18 & 15.03 \\
\hline 11 & 2.55 & 11.27 \\
\hline 12 & 2.18 & 15.03 \\
\hline 13 & 2.87 & 19.73 \\
\hline 14 & 2.55 & 11.27 \\
\hline 15 & 2.55 & 14.09 \\
\hline 16 & 1.43 & 9.86 \\
\hline 17 & 2.55 & 17.54 \\
\hline 18 & 2.87 & 15.78 \\
\hline 19 & 2.19 & 15.03 \\
\hline 20 & 2.55 & 17.54 \\
\hline 21 & 2.55 & 11.27 \\
\hline 22 & 2.55 & 11.27 \\
\hline 23 & 2.55 & 17.54 \\
\hline Ave & 2.09 & 12.73 \\
\hline
\end{tabular}

(b) DNO Network Asset Embodied $\mathrm{CO}_{2}$ by Hybrid Functional Units of Length, Capacity and Units of Electricity Delivered

\begin{tabular}{|c|c|c|}
\hline DNO & $\begin{array}{l}\text { Embodied } \mathrm{CO}_{2} \\
(\mathrm{~kg} / \mathrm{MW} / \mathrm{km})\end{array}$ & $\begin{array}{l}\text { Embodied } \mathrm{CO}_{2} \\
(\mathrm{~g} / \mathrm{MWh} / \mathrm{km})\end{array}$ \\
\hline 10 & 79.0 & 16.2 \\
\hline 11 & 110.2 & 21.7 \\
\hline 12 & 145.7 & 27.2 \\
\hline 13 & 144.9 & 31.3 \\
\hline 14 & 111.9 & 22.0 \\
\hline 15 & 194.0 & 35.1 \\
\hline 16 & 186.9 & 27.1 \\
\hline 17 & 351.5 & 67.1 \\
\hline 18 & 112.8 & 25.3 \\
\hline 19 & 154.9 & 30.2 \\
\hline 20 & 87.1 & 16.6 \\
\hline 21 & 208.8 & 37.4 \\
\hline 22 & 144.1 & 29.4 \\
\hline 23 & 147.4 & 27.3 \\
\hline Ave & 155.66 & 29.5 \\
\hline
\end{tabular}

Figure 6: Embodied $\mathrm{CO}_{2}$ of Network Assets according to different Hybrid Functional Units 


\subsection{Environmental Discounting}

Discounting is an approach used in many fields, most notably economics, where Net Present Value (NPV) is a well established metric used to account for the changing value of money over time. It portrays money in the future in terms of its value today. Money today is deemed higher value than money in the future, so future money is discounted, using a set discount rate - which may represent asset value, risk or expected inflation among other factors.

Environmental discounting has adopted this method with three main approaches. One adopts the economic method directly, using a $\mathrm{CO}_{2}$ discount rate across a set timescale [56]. Another uses a more complex methods, where emissions are accounted for at the time of release and their interaction with the environment is modelled [57] - this approach is used to account for other environmental impacts as well as carbon dioxide and is deemed out of the scope of this study - for which $\mathrm{CO}_{2}$ across a large system is considered. The final approach applies a social aspect - accounting for the social impact as well as the direct environmental impact of $\mathrm{CO}_{2}$ emissions over time [58].

A range of suggested discount rates and methods to calculate $\mathrm{CO}_{2}$ discount rates in varying complexities can be found in the literature. However, for the purpose of this paper, a discount rate of 0.674 is used as a suggested discount rate for emissions taking place in 2015 [56]. This discount rate is low - it places high weighting on $\mathrm{CO}_{2}$ emitted today. This low discount rate reflects the urgency in meeting global climate change targets and the fact that timely reductions in emissions is considered cheaper and more effective than interventions later. In the application of this discount rate, both the operational and embodied $\mathrm{CO}_{2}$ of the generation and network assets must be considered. An annual accounting approach is used, where generation during the whole year is discounted at the same rate. Due to the nature of electricity generation and the timescales considered, it would be inappropriate to calculate at lower resolutions.

Applying the discount rate to calculations that use functional units that account for asset lifetime and units of electricity delivered will allow for an assessment of the contribution of network asset embodied $\mathrm{CO}_{2}$ in comparison to operational $\mathrm{CO}_{2}$ for a given network.

\section{Using Hybrid Functional Units to Calculate Embodied $\mathrm{CO}_{2}$ of Network Assets}

A recent LCA study of the GB Transmission Network used the functional unit of $(\mathrm{kg} / \mathrm{kWh})$ in order to calculate the total contribution of embodied $\mathrm{CO}_{2}$ to the total $\mathrm{CO}_{2}$ of electricity generation and transmission [8]. This is a useful metric in order to see the importance of embodied $\mathrm{CO}_{2}$ in a whole electricity system. However, due to the changing nature of the electricity system as previously discussed, it is important to look at how this relationship may change as the system evolves. The study used the assumption that network assets had an expected lifetime of 40 years and assumed static demand over the 40 year period. It also assumed no change in the carbon intensity of the operational grid $\mathrm{CO}_{2}$ or in the network asset composition.

In this paper, five scenarios are used for both the transmission network and distribution network:

1. The changes in electricity demand and operational grid carbon intensity are accounted for using publicly available data to update work by other academics. The average asset lifetime is kept static and no changes to the 
network assets are considered.

2. Several temporal horizons are suggested and the same calculations are carried out for each timeframe. A comparison of results is used to analyse the impact that a temporal horizon can have on calculation of $\mathrm{CO}_{2}$.

3. Data on the changes to the transmission and distribution level assets over a set planning time frame is considered as a case study to show how investment in the network can impact the calculation of embodied $\mathrm{CO}_{2}$.

4. The investment data is then extrapolated and applied to the other suggested temporal horizons to give indication of investment impact over a longer timeframe.

5. The same calculations are repeated using the functional unit of $\mathrm{kg} / \mathrm{kW}$ and the hybrid functional units $\mathrm{kg} / \mathrm{k}-$ $\mathrm{Wh} / \mathrm{km}, \mathrm{kg} / \mathrm{kWh} / \mathrm{yr}$ and $\mathrm{kg} / \mathrm{kW} / \mathrm{km}$ and $\mathrm{kg} / \mathrm{kWh} / \mathrm{km}$.

For each of these scenarios, there are a number of variables to be considered including electricity demand as previously discussed. However, grid operational emissions and temporal horizons need further explanation before their use in the five scenarios.

\subsection{Grid Operational Emissions}

There are two major components to operational emissions associated with grid electricity: carbon intensity of the generation mix and overall electricity demand. Predictions for both of these over time are publicly available. Operational carbon intensity data is depicted in Figure 8 taken from emissions reports [59] and from predictions made by the UK Department of Energy and Climate Change [59]. There are many organisations which outline potential future electricity generation scenarios for the UK and its transition to a low carbon electricity supply. Figure 8 shows the two predictions by the UK Government - similarly to the future demand predictions shown in Figure 7 the two predictions represent 'business as usual' and the impact of UK Government policies. It can be seen from Figure 8 that policies are aiming to reduce the carbon intensity of electricity generation significantly. These two future electricity demand predictions provide ultimately two scenarios which are considered in each of the calculations.

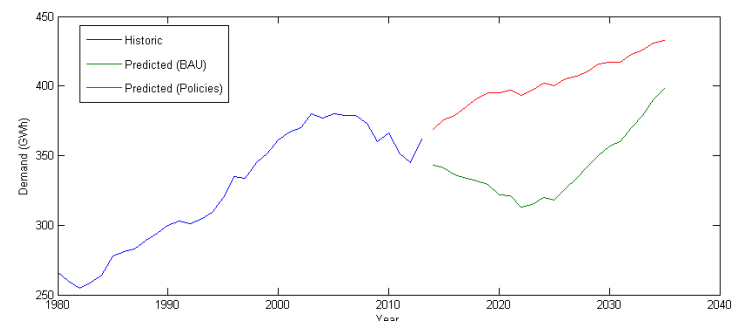

Figure 7: Future Predicted Electricity Demand in the GB Network

\subsection{Temporal Horizons}

Accounting for the different expected lifetime of assets and the changing network asset composition is more challenging and involves defining a timescale for the assessment. Defining a suitable timescale, or temporal horizon, 


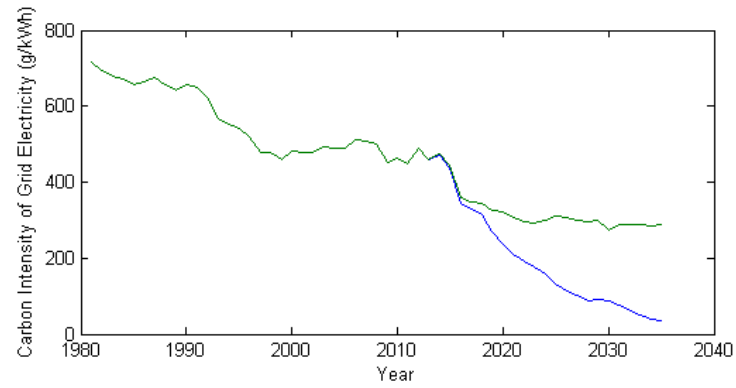

Figure 8: Historical and Predicted Carbon Intensity of Electricity in the GB Network [59]

is noted as a challenging issue in LCA. For a product, the temporal horizon would usually be defined as the product lifetime. For an electricity network, defining the product lifetime is challenging as the network is constantly changing and each component has differing expected lifetimes.

Temporal Horizon selection is inherently linked to environmental discounting - as the selection of the temporal horizon impacts the effect of the environmental discounting.

In order to compare results to the previous study, a temporal horizon of 40 years must be considered, to allow understanding of the impact of changing the other variables on the results. Other temporal horizons are also considered and are shown in Table 6

Table 6: A Selection of Possible Temporal Horizons for Electricity Network Calculations

\begin{tabular}{ll}
\hline Temporal Horizon Description & $\begin{array}{l}\text { Length } \\
(\mathrm{yrs})\end{array}$ \\
\hline $\begin{array}{ll}\text { Average Expected Lifespan of Distribution } \\
\text { Level Assets }\end{array}$ & 54 \\
Average Expected Lifespan of Transmission & 38 \\
Level Assets & \\
Current Planning Framework in the GB & 8 \\
Network (RIIO) & \\
\hline
\end{tabular}

The 8 year planning period can be dealt with in two ways. Firstly, network asset embodied $\mathrm{CO}_{2}$ could be considered as emitted during these 8 years for the whole network. This consideration is unrealistic and would provide an overestimate of the embodied $\mathrm{CO}_{2}$ due to the much longer expected lifetime and would include all previously emitted embodied $\mathrm{CO}_{2}$ in existing network assets. However, this approach can be used to 'front load' the embodied $\mathrm{CO}_{2}$ of network assets. As discussed in the environmental discounting section front loading accounts for the urgency in reducing $\mathrm{CO}_{2}$ emissions in order to meet global emissions reductions targets. Another approach would be to consider only a percentage of the embodied $\mathrm{CO}_{2}$ in the ratio of planning framework years to expected lifetime, by applying 
Equation 3, which allows for only a proportion of the embodied $\mathrm{CO}_{2}$ to be considered during a planning framework.

$$
E C_{P F}=E C_{D N O} \frac{T_{P F}}{T_{D N O}}
$$

\subsection{Distribution Network Results}

Using a static 40 year asset lifetime and static demand over the same 40 year period, calculations for each DNO region are also made in order to show the regional differences in comparison to the whole network look at transmission level. The calculations involve using demand data from each DNO in 2013, shown in Table 7 and applying them to Equation 4, which calculates the total grid operational $\mathrm{CO}_{2}$ expected over the chosen temporal horizon in order to calculate the embodied to operational $\mathrm{CO}_{2}$ ratio. In the case of a static 40 year time frame with static grid emissions factor, y in Equation 4 is taken as 2013.

$$
R E O_{D N O}=\frac{E C_{D N O}}{E F_{y} T H_{L C A} D_{y}+E C_{D N O}}
$$

The results, shown in Table 7, highlight the regional differences in the DNO network asset composition and the effect that demand has on the calculations. It also shows that in comparison with Harrison's work at TNO level estimating an embodied $\mathrm{CO}_{2}$ to operational carbon ratio of $4 \%[8]$, under the same demand and carbon intensity calculations the DNO level ratios are higher. This relationship shows that the DNO level assets can have considerably higher contribution to overall network $\mathrm{CO}_{2}$ in comparison to TNO network assets. This is particularly true in DNO region 17 , where network embodied $\mathrm{CO}_{2}$ contributes over $13 \%$ of total $\mathrm{CO}_{2}$ emissions associated with electricity.

In order to account for changing demand and grid emissions factors over the course of a given time period, the use of Equation 4 becomes part of an annual accounting technique. Each annual emissions factor is taken from the data used to create Figure 8 and demand from Figure 7 . Due to the available data, total GB demand is split into each DNO region on the assumption that the ratio of demand will remain the same as in 2013. The ratio is calculated each year, for each DNO region by calculating the embodied carbon intensity over the temporal horizon, using Equation 5 and then substituting this embodied carbon intensity into Equation 6 to give the annual ratio. These calculations are carried out based on both the baseline 'business as usual' demand and emissions forecasts as well as the UK Government Policy demand and emissions forecasts.

$$
\begin{gathered}
E C I_{T H}=\frac{E C_{D N O}}{\sum_{y=y 1}^{y n} D_{y}} \\
R E O_{D N O}=\frac{E C I_{T H}}{E F_{y}+E C I_{T H}}
\end{gathered}
$$


Table 7: DNO Regional embodied $\mathrm{CO}_{2}$ Percentage Calculations for a 40 year static demand

\begin{tabular}{lll}
\hline DNO & $\begin{array}{l}\text { Demand in } \\
2013\end{array}$ & $\begin{array}{l}\text { Ratio Embodied to } \\
\text { Operational Carbon } \\
\end{array}$ \\
& $(\mathrm{GWh})$ & $(\%)$ \\
\hline 10 & 34,000 & 6.95 \\
11 & 26,913 & 6.98 \\
12 & 29,000 & 4.50 \\
13 & 17,000 & 6.74 \\
14 & 24,409 & 6.33 \\
15 & 15,500 & 6.40 \\
16 & 23,484 & 6.90 \\
17 & 8,346 & 13.34 \\
18 & 21,000 & 6.49 \\
19 & 21,000 & 7.01 \\
20 & 33,172 & 5.77 \\
21 & 11,833 & 5.92 \\
22 & 22,700 & 6.59 \\
23 & 1,134 & 6.52 \\
\hline & &
\end{tabular}


The annual embodied to operational carbon ratio for both baseline and low carbon policy forecasts are shown in Figure 9 and Figure 10 . It can be seen that similarly to the TNO level results, including demand and emissions forecasting makes a significant difference to the results. For clarity, the ratios for 2035 for each DNO are shown in Table 8 for both baseline and low carbon policies forecasts. The results show that by 2035 , taking into consideration the low carbon policies of the UK Government, the DNO embodied $\mathrm{CO}_{2}$ reaches a minimum of $42 \%$ of total grid carbon and in one region - region 17 - the embodied $\mathrm{CO}_{2}$ of the network is higher than the operational carbon of the electricity the DNO delivers.

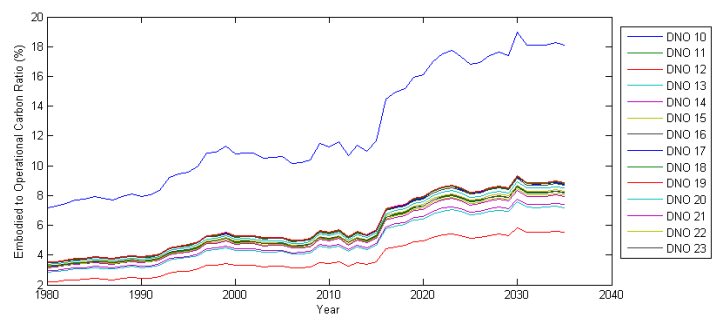

Figure 9: DNO Embodied to Operational Carbon with UK Government Baseline Emissions and Demand Forecasts

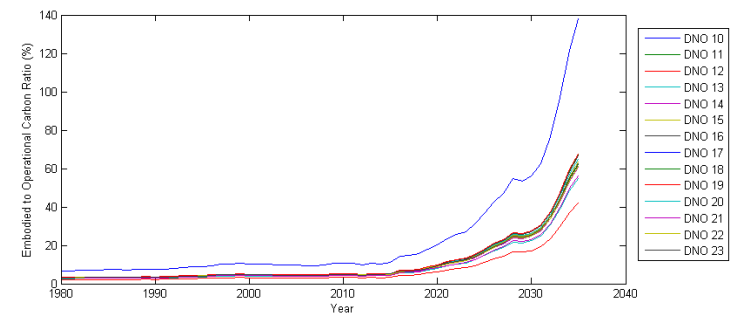

Figure 10: DNO Embodied to Operational Carbon with UK Government Low Carbon Policy Emissions and Demand Forecasts

\subsection{Transmission Network Results}

For the transmission network level assets, a temporal horizon of 38 years is used, as the average expected lifetime of network assets [60]. Each annual emissions factor is taken from the data used to create Figure 8 and demand from Figure 7 as with the DNO level calculations. The ratio is calculated each year by calculating the embodied carbon intensity over the temporal horizon, using Equation 7 and then substituting this embodied carbon intensity into Equation 8 to give the annual ratio in the same approach as with the DNO level calculations, on both the baseline 'business as usual' demand and emissions forecasts as well as the UK Government Policy demand and emissions forecasts. The results, shown in Figure 11 show that when UK Government Policies are considered, transmission level assets could contribute up to $30 \%$ of total grid carbon by 2035 . When considering low carbon electricity plans 
Table 8: DNO Regional embodied $\mathrm{CO}_{2}$ Percentage Calculations for a 54 year Temporal Horizon

\begin{tabular}{lll}
\hline & $\begin{array}{l}\text { Baseline } \\
(\%)\end{array}$ & $\begin{array}{l}\text { Policies } \\
(\%)\end{array}$ \\
\hline DNO & 2035 & 2035 \\
\hline 10 & 8.78 & 66.94 \\
11 & 8.81 & 67.20 \\
12 & 5.53 & 42.40 \\
13 & 8.49 & 64.74 \\
14 & 7.94 & 60.57 \\
15 & 8.04 & 61.31 \\
16 & 8.71 & 66.44 \\
17 & 18.09 & 137.93 \\
18 & 8.16 & 62.24 \\
19 & 8.86 & 67.58 \\
20 & 7.20 & 54.91 \\
21 & 7.39 & 56.36 \\
22 & 8.29 & 63.22 \\
23 & 8.20 & 62.53 \\
\hline & & \\
\hline
\end{tabular}


for a country at policy level, embodied $\mathrm{CO}_{2}$ becomes an important component that is currently being largely ignored.

$$
\begin{gathered}
E C I_{T H}=\frac{E C_{S O}}{\sum_{y=y 1}^{y n} D_{y}} \\
R E O_{S O}=\frac{E C I_{T H}}{E F_{y}+E C I_{T H}}
\end{gathered}
$$

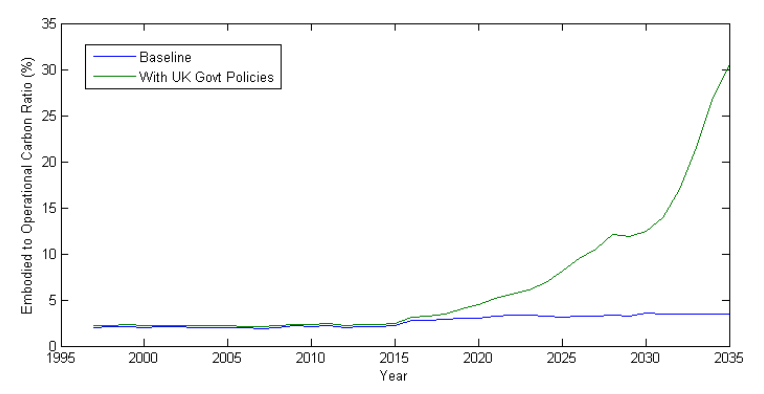

Figure 11: Historic and Predicted Contribution of embodied $\mathrm{CO}_{2}$ of Network Assets to Total Grid Electricity Carbon in the GB Network on a 38 year timescale

\subsection{Accounting for Asset Losses and Gains}

Electricity networks are ever changing - network upgrades and expansion mean that there are always old assets being decommissioned or upgraded and new assets being commissioned on a regular basis. This is particularly true in times of network expansion, which many global networks are currently experiencing. As generation facilities reach end of life, the generation mix is moving to a more distributed form and renewable energy providing new expansion areas for electricity networks. Offshore wind generation is seeing network cables reach the very edge of countries and transmission network assets are reaching further to areas of high renewable resource. Accounting for the changes in a network over the lifespan of an LCA requires investment and asset data in addition to the data previously studied in this paper.

While it has already been shown that it would be inappropriate to allocate the embodied $\mathrm{CO}_{2}$ of all current network assets to an investment planning period, it could be useful to allocate all of the new asset carbon built within the planning framework to its temporal horizon. This 'front loads' the new embodied emissions.

\subsection{Impact of RIIO-EDI and RIIO-T1 Investment}

As a case study, investment data is taken from the 14 GB DNO regions and the SO over the current investment planning timeframe of 8 years from 2015-2023. Electricity North West have published the new requirements for cable 
Table 9: DNO Estimated New Asset Requirements [61]

\begin{tabular}{llll}
\hline DNO & $\begin{array}{l}\text { New OHL } \\
\text { per year }\end{array}$ & $\begin{array}{l}\text { New UGC } \\
\text { per year } \\
(\mathrm{km})\end{array}$ & $\begin{array}{l}\text { RIIO Carbon } \\
\text { per year }\end{array}$ \\
& $(\mathrm{km})$ & $(\mathrm{t})$ \\
\hline 10 & 2,877 & 282 & 552,355 \\
11 & 1,862 & 227 & 392,856 \\
12 & 0 & 164 & 129,138 \\
13 & 1,547 & 135 & 284,043 \\
14 & 2,031 & 182 & 376,393 \\
15 & 1,252 & 117 & 236,174 \\
16 & 1,100 & 200 & 283,993 \\
17 & 1,375 & 143 & 270,692 \\
18 & 1,837 & 160 & 337,301 \\
19 & 1,015 & 182 & 259,940 \\
20 & 2,299 & 226 & 441,715 \\
21 & 1,523 & 77 & 235,662 \\
22 & 2,369 & 100 & 350,642 \\
23 & 1,134 & 181 & 272,808 \\
\hline
\end{tabular}

investment between 2010 and 2015 [11]. Calculations are only carried out for DNO level assets due to the available data. Based on the assumption that the Electricity North West data is representative of new annual asset requirements as a percentage of existing assets, the annual asset requirements for the other DNOs are calculated and shown in Table 9. Also shown in Table 9 is the annual embodied $\mathrm{CO}_{2}$ over the 8 year planning period of these new investments.

Calculations are carried out front loading the $\mathrm{CO}_{2}$ emissions of new investment during the planning framework timeframe whilst applying the environmental discounting method. This approach means that an annual accounting of $\mathrm{CO}_{2}$ emissions is required. For each year, the emissions are calculated and the discount rate applied. The annual embodied to operational carbon percentages of the new network assets are shown in Figure 12 and show that when front loaded over the appropriate investment period, new network asset embodied $\mathrm{CO}_{2}$ can contribute up to $6.5 \%$ of total emissions of grid electricity. This result shows that embodied $\mathrm{CO}_{2}$ of network assets is important to consider not just in total network level, but at new investment level. Over the next 8 year planning period in the GB market, network investment will increase the carbon associated with electricity from the network by a significant amount. 


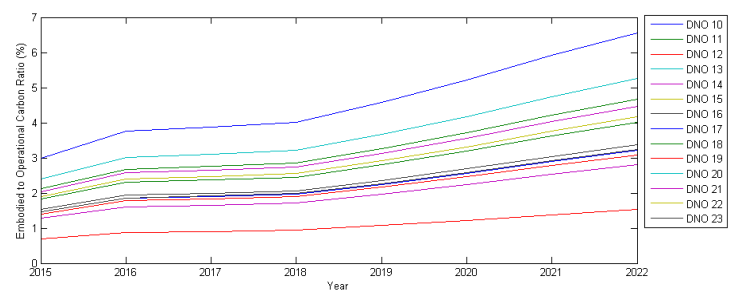

Figure 12: Predicted Contribution of embodied $\mathrm{CO}_{2}$ of Network Assets due to Investment in RIIO-ED1 8 Year Period

\section{Discussion}

Electricity is a vital part of modern life and the importance of measuring its environmental impact is an issue of ever growing importance. It is for this reason that LCA of electricity networks should include the network assets, which in the GB networks contribute a total of 446 mtonnes across the transmission and distribution network.

The way in which embodied $\mathrm{CO}_{2}$ is valued - according to different functional units, is key in ensuring that embodied $\mathrm{CO}_{2}$ is compared to operational carbon in an equal manner. This paper has shown that singular functional units are not appropriate for electricity network assets due to a number of factors including the complexity of the system, the lifetime of the network assets and the variety of stakeholders involved. A traditional functional unit in the construction industry of unit length accounts for the materials but fails to account for the purpose of a unit length of network asset. A traditional functional unit for electricity generation technologies of unit electricity delivered inherently requires the asset lifetime information and expected future demand. The many aspects that need to be reflected when allocating embodied $\mathrm{CO}_{2}$ to function mean it is more appropriate to use hybrid functional units when analysing electricity networks.

Adopting hybrid functional units that cope with asset lifetimes and changing demands means facing the issue of temporal scale in LCA which is a well documented challenge facing LCA methodology. In order to overcome the challenge of temporal horizons in LCA of electricity networks, two approaches are taken. An average of the network asset expected lifetimes for both the SO level and each DNO region are taken. In addition to this, calculations are made over a much shorter time period to represent a GB planning investment framework. Calculations show that over the whole asset lifetime, by 2035 embodied $\mathrm{CO}_{2}$ of network assets could reach $30 \%$ of total grid carbon at transmission level (Figure 11) and between $42 \%$ and $137 \%$ at DNO level depending on the region (Figure 10).

Although at a technical level, it may be appropriate to calculate the emissions of network assets according to their whole lifetime, there are two challenges in managing this. Firstly, network asset lifetimes can be up to 80 years, and electricity demand and emissions forecasts rarely reach this far into the future. Secondly, network assets vary in expected lifetime and LCA would have to be carried out on several temporal horizons based on each network asset. For a policy level, front loading the embodied $\mathrm{CO}_{2}$ of network assets to align with the investment period that they are built in could be an appropriate manner to deal with network embodied $\mathrm{CO}_{2}$. This approach would mean that investment planning frameworks were dealt with in isolation and would provide a clear way for a regulator, for 
example Ofgem, to compare between DNO regions. Calculations show that front loading new investment embodied emissions mean that during RIIO-ED1 new investment can account for $6.5 \%$ of total grid emissions (Figure 12).

While carbon intensity of the generation mix and predicted demand data are estimated annually, change in peak demand and new cable requirements are interpolated based on a linear annual change between published predictions across the RIIO-ED1 and RIIO-T1 period. The use of distributed generation (DG) and demand side management (DSM) is increasing across the world and the impact this may have on network investment through minimised losses and reduction in peak demand. This paper has looked at peak demand predictions which to a certain extent include expected use of DG and DSM. However, both DG and DSM could have an impact on the carbon intensity data and demand data depending on their uptake.

As the operational carbon associated with generation technologies reduces, the embodied $\mathrm{CO}_{2}$ of network assets will contribute a higher percentage to total carbon associated with grid electricity. It is important that appropriate calculations of embodied $\mathrm{CO}_{2}$ of network assets are used in order to make policy level decisions accounting for the whole impact of policies. It is becoming more normal increasingly common in the construction industry to compare the operational carbon associated with the building life to the embodied $\mathrm{CO}_{2}$ in its materials, construction and decommissioning. This approach should be adopted for other systems including electricity networks.

\section{Future Work}

Currently, the network asset embodied $\mathrm{CO}_{2}$ inventory is based on transmission level assets. In reality, embodied $\mathrm{CO}_{2}$ of distribution level assets is likely to be different and it is suggested that a distribution level embodied $\mathrm{CO}_{2}$ inventory would be beneficial in further investigation of embodied $\mathrm{CO}_{2}$ of network assets.

The current work has used the GB network as a case study and has already shown regional differences between DNO regions due to differences in network components and demand. It would be useful to compare the results in an international context, particularly at transmission level where the generation carbon intensity calculations are based. Electricity networks across the world face different challenges in the transition to a lower carbon supply and the importance of embodied $\mathrm{CO}_{2}$ of network assets will differ depending on the generation mix and network components. In addition to this, the interconnected nature of many global electricity networks, including the GB network, adds another complexity. Although the carbon intensity of the generation for electricity imports is accounted for in DECC's historic and predicted data, the embodied $\mathrm{CO}_{2}$ of network assets in the interconnectors and the assets of the importing electricity network should also be included where possible.

\section{Conclusion}

The embodied $\mathrm{CO}_{2}$ of network assets is not often considered when investigating network assets. This paper used a range of functional units to highlight the complex nature of carrying out LCA of electricity network assets and the importance of understanding network asset lifetimes. The paper then used hybrid functional units and environmental 
discounting to assess the impact of future low carbon generation mixes on network asset embodied $\mathrm{CO}_{2}$ and account for time, length, capacity and electricity delivered. Previous work in this field has shown the contribution of embodied $\mathrm{CO}_{2}$ network assets to total grid carbon based on a number of assumptions. Using publicly available data and drawing on a number of LCA methods, this paper has improved upon these previous studies. By accounting for changing electricity demand, future generation mixes, investment into network infrastructure and by using expected lifetime data, the paper has shown that in the future embodied $\mathrm{CO}_{2}$ of network assets could be between $42 \%$ and $137 \%$ of the operational carbon associated with electricity generation. It is recommended that this approach should be used at regulatory level in order to allow for a holistic understanding of future electricity systems to be made.

It has been shown that the transition to a low carbon electricity supply will mean an increased contribution from embodied $\mathrm{CO}_{2}$ of network assets to total carbon associated with grid electricity. The ratio of embodied $\mathrm{CO}_{2}$ to operational carbon depends on the functional units used and the temporal horizon selected. The paper has dealt with two types of LCA calculation: averaging network embodied emissions over the asset lifetime and calculating front loaded emissions of network investment. The two approaches each have merit for different situations: the first allows for a historic look at network emissions in totality and could be applied in future scenarios where network investment is minimal. The second approach is an approach suitable for use when considering network investment strategies and when analysing future low carbon electricity generation scenarios. It is in these scenarios that embodied $\mathrm{CO}_{2}$ of network assets has supreme importance; leaving embodied $\mathrm{CO}_{2}$ from calculations at investment planning stage could mean decisions are made without the whole picture - meaning future electricity scenarios have different impacts than originally calculated.

\section{Acknowledgements}

The authors would like to thank Marks and Spencer, Matrix Controls Solutions, and the EPSRC for their ongoing support and funding of the Technologies for Sustainable Built Environments Centre (Grant No. EP/G037787/1).

\section{Nomenclature}

$D_{y} \quad$ Demand in a given in the DNO region $(\mathrm{kWh})$

$D G \quad$ Distributed Generation

DNO Distribution Network Operator

DSM Demand Side Management

Dx Distribution Network

$E C_{\text {Demand }}$ Embodied $\mathrm{CO}_{2}$ - Capacity Metric (kg/MW)

$E C_{D N O} \quad$ DNO Embodied Emissions $(\mathrm{kg})$

$E C_{P F} \quad$ Embodied $\mathrm{CO}_{2}$ during Planning Framework $(\mathrm{kg})$

$E C_{S O} \quad$ Transmission Level Network Assets embodied $\mathrm{CO}_{2}(\mathrm{~kg})$ 


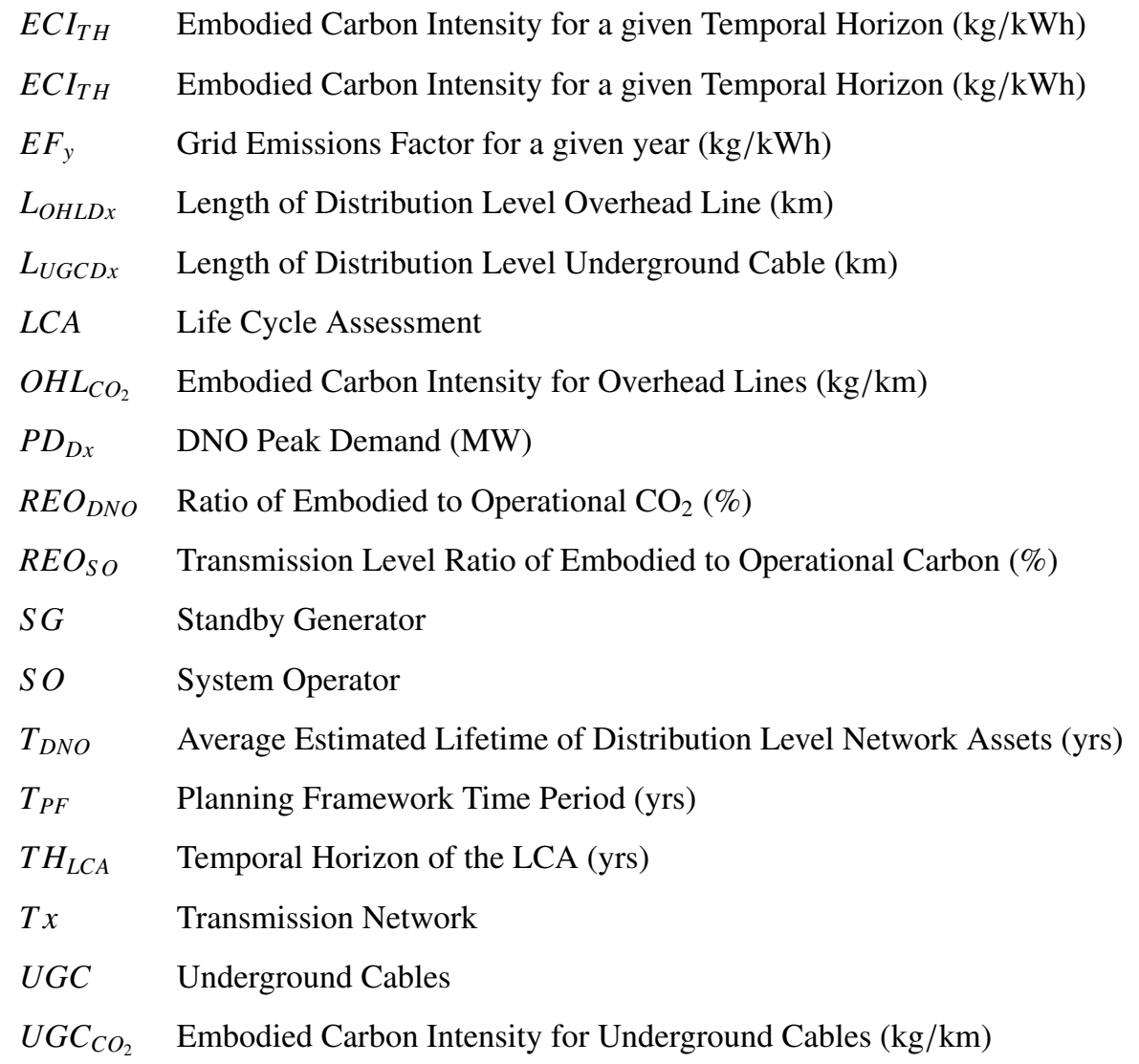

\section{References}

[1] A. Hawkes, Estimating marginal CO2 emissions rates for national electricity systems Energy Policy 38 (10) (2010) 5977-5987. doi: $10.1016 / j$.enpol.2010.05.053

URL linkinghub.elsevier.com/retrieve/pii/S0301421510004246

[2] R. S. Jorge, E. G. Hertwich, Environmental evaluation of power transmission in Norway Applied Energy 101 (2013) 513-520. doi: 10.1016/j.apenergy.2012.06.004 URL linkinghub.elsevier.com/retrieve/pii/S030626191200445X

[3] H. Lund, B. V. Mathiesen, P. Christensen, J. H. Schmidt, Energy system analysis of marginal electricity supply in consequential LCA The International Journal of Life Cycle Assessment 15 (3) (2010) 260-271. doi:10.1007/s11367-010-0164-7 URL link.springer.com/10.1007/s11367-010-0164-7

[4] B. V. Mathiesen, M. Münster, T. Fruergaard, Uncertainties related to the identification of the marginal energy technology in consequential life cycle assessments. Journal of Cleaner Production 17 (15) (2009) 1331-1338. doi:10.1016/j.jclepro. 2009.04.009 URL linkinghub.elsevier.com/retrieve/pii/S0959652609001462

[5] D. T.-C. Wang, L. F. Ochoa, G. P. Harrison, DG Impact on Investment Deferral: Network Planning and Security of Supply IEEE Transactions on Power Systems 25 (2) (2010) 1134-1141. doi:10.1109/TPWRS.2009.2036361 URL ieeexplore.ieee.org/lpdocs/epic03/wrapper.htm?arnumber=5371954

[6] D. Zafirakis, K. J. Chalvatzis, G. Baiocchi, G. Daskalakis, Modeling of financial incentives for investments in energy storage systems that promote the large-scale integration of wind energy Applied Energy 105 (2013) 138-154. doi:10.1016/j .apenergy.2012.11.073 URL linkinghub.elsevier.com/retrieve/pii/S0306261912008823 
[7] D. Q. Hung, N. Mithulananthan, R. Bansal, An optimal investment planning framework for multiple distributed generation units in industrial distribution systems Applied Energy 124 (2014) 62-72. doi:10.1016/j . apenergy.2014.03.005 URL http://linkinghub.elsevier.com/retrieve/pii/S030626191400227X

[8] G. P. Harrison, E. N. J. Maclean, S. Karamanlis, L. F. Ochoa, Life cycle assessment of the transmission network in Great Britain Energy Policy 38 (7) (2010) 3622-3631. doi:10.1016/j.enpol.2010.02.039 URL linkinghub.elsevier.com/retrieve/pii/S0301421510001205

[9] L. Daniels, P. Coker, A. Gunn, B. Potter, Using proxies to calculate the carbon impact of investment into electricity network assets Applied Energy 162 (2016) 551-560. doi:10.1016/j.apenergy . 2015.10.111 URL linkinghub.elsevier.com/retrieve/pii/S0306261915013471

[10] L. Daniels, B. Potter, P. Coker, Exploring Methods to Evaluate the Carbon Impact of Network Investment Deferral, in: Innovative Smart Grid Technologies Conference Europe (ISGT-Europe), 2014 IEEE PES, 2014, pp. 1-6.

[11] Electricity North West, Network Investment Plan 2010-2015, Tech. rep. (2009).

[12] Electricity Networks Strategy Group, Our Electricity Transmission Network : A vision for 2020, Tech. Rep. February 2012 (2012).

[13] The Green Construction Board, Infrastructure Carbon Review Technical Report, Tech. rep. (2013).

[14] United Nations Framework Convention on Climate Change, Baseline Methodology Procedure," in Tool to calculate the emission factor for an electricity system, Tech. rep. (2008).

[15] UN Environment Programme, Global Guidance Principles for Life Cycle Assessment Databases: A Basis for Greener Processes and Products, Tech. rep. (2011).

[16] R. Brizmohun, T. Ramjeawon, A. Azapagic, Life cycle assessment of electricity generation in Mauritius Journal of Cleaner Productior doi: $10.1016 / \mathrm{j} \cdot \mathrm{jclepro} .2014 .11 .033$ URL www.sciencedirect.com/science/article/pii/S095965261401213X

[17] R. Turconi, A. Boldrin, T. Astrup, Life cycle assessment (LCA) of electricity generation technologies: Overview, comparability and limitations Renewable and Sustainable Energy Reviews 28 (2013) 555-565. doi:10.1016/j.rser.2013.08.013 URL linkinghub.elsevier.com/retrieve/pii/S1364032113005534

[18] A. Hawkes, Long-run marginal CO2 emissions factors in national electricity systems Applied Energy 125 (2014) 197-205. doi:10.1016/ j.apenergy.2014.03.060 URL linkinghub.elsevier.com/retrieve/pii/S0306261914003006

[19] G. Finnveden, M. Z. Hauschild, T. Ekvall, J. Guinée, R. Heijungs, S. Hellweg, A. Koehler, D. Pennington, S. Suh, Recent developments in Life Cycle Assessment. Journal of environmental management 91 (1) (2009) 1-21. doi:10.1016/j j jenvman.2009.06.018 URL/www.sciencedirect.com/science/article/pii/S0301479709002345

[20] S. Hellweg, R. Frischknecht, Evaluation of Long-Term Impacts in LCA The International Journal of Life Cycle Assessment 9 (5) (2004) 339-341. doi:10.1007/BF02979427 URL http://link.springer.com/10.1007/BF02979427

[21] M. Messagie, J. Mertens, L. Oliveira, S. Rangaraju, J. Sanfelix, T. Coosemans, J. Van Mierlo, C. Macharis, The hourly life cycle carbon footprint of electricity generation in Belgium, bringing a temporal resolution in life cycle assessment Applied Energy 134 (2014) 469-476. doi:10.1016/j.apenergy.2014.08.071

URL www.sciencedirect.com/science/article/pii/S0306261914008824

[22] J. Reap, F. Roman, S. Duncan, B. Bras, A survey of unresolved problems in life cycle assessment Part 2: impact assessment and interpretation The International Journal of Life Cycle Assessment 13 (5) (2008) 374-388. doi:10.1007/s11367-008-0009-9 URL link.springer.com/10.1007/s11367-008-0009-9

[23] Electricity North West, Electricity North West Business Plan, Tech. rep. (2013).

[24] UK Power Networks, Business Plan for Our Electricity Network for London, Tech. Rep. November 2012 (2012).

[25] UK Power Networks, Business plan for our electricity network for East of England, Tech. rep. (2012). 
[26] UK Power Networks, Business Plan for Our Electricity Network for South East England, Tech. Rep. November 2012 (2012).

[27] Western Power Distribution, WPD South West Business Plan Key Facts About our Network, Tech. rep. (2013).

[28] Western Power Distribution, WPD South Wales Business Plan Key Facts about Our Network, Tech. rep. (2013).

[29] Western Power Distribution, WPD West Midlands Business Plan Key Facts About our Network, Tech. rep. (2013).

[30] Western Power Distribution, WPD East Midlands Business Plan Key Facts, Tech. rep. (2013).

[31] Northern Powergrid, Emerging Thinking for 2015 and Beyond, Tech. rep. (2013).

[32] Northern Powergrid, Northern Powergrid (Yorkshire) plc Business Plan: Key Facts about our Network, Tech. rep.

[33] Scottish and Southern Energy Power Distribution, Technical Appendix 08.1 - Expenditure Tech. rep. (dec 2013). URL www.ncbi.nlm.nih.gov/pubmed/20027557LastAccessed09/05/2016

[34] Scottish and Southern Energy Power Distribution, SSE Hydro Business Plan Key Facts About our Network, Tech. Rep. April (2015).

[35] Scottish and Southern Energy Power Distribution, SSE Southern Business Plan Key facts About Our Network, Tech. Rep. April (2013).

[36] Scottish Power, SP Manweb Business Plan, Tech. rep. (2013). doi:10.1117/3.1001180.ch7

[37] H. Alderson, G. R. Cranston, G. P. Hammond, Carbon and environmental footprinting of low carbon UK electricity futures to 2050 Energy 48 (1) (2012) 96-107. doi:10.1016/j .energy .2012.04.011 URL linkinghub.elsevier.com/retrieve/pii/S0360544212002915

[38] Western Power Distribution, Western Power Distribution ( South Wales ) plc Regulatory Financial Statements (2012).

[39] Western Power Distribution, Western Power Distribution ( South West ) plc Regulatory Financial Statements (2012).

[40] Western Power Distribution, Weatern Power Distribution (East Midlands) plc Regulatory Financial Statements (2012).

[41] Western Power Distribution, Western Power Distribution ( West Midlands ) plc Regulatory Financial Statements, Tech. Rep. March (2014).

[42] UK Power Networks, London Power Networks Regulatory Accounts (2014).

[43] UK Power Networks, South Eastern Power Networks Regulatory Accounts (2014).

[44] UK Power Networks, Eastern Power Networks Regulatory Accounts (2013).

[45] Scottish Power, Scottish Power Distribution Regulatory Accounts (2014).

[46] Scottish Power, Scottish Power Manweb Regulatory Accounts (2014).

[47] Scottish and Southern Energy Power Distribution, Scottish Hydro Electric Power Distribution plc Regulatory Financial Statements Year ended 31 March 2014 (2014).

[48] Scottish and Southern Energy Power Distribution, Southern Electric Power Distribution plc Regulatory Financial Statements (2014).

[49] Electricity North West, Electricity North West Limited Annual Report and Consolidated Regulatory (2013).

[50] Northern Powergrid, Northern Power Grid (Yorkshire) Limited Regulatory Accounts (2013).

[51] Northern Powergrid, Northern Power Grid (Northeast) Limited Regulatory Accounts, Tech. rep. (2013).

[52] Department of Energy and Climate Change, Digest of United Kingdom Energy Statistics 2012, Tech. Rep. July (2012).

[53] Department of Energy and Climate Change, Capturing the full electricity efficiency potential of the UK, Tech. Rep. July (2012).

[54] Ofgem, RIIO-T1 : Final Proposals for National Grid Electricity Transmission and National Grid Gas Cost assessment and uncertainty Supporting Document, Tech. rep. (2012).

[55] Ofgem, Electricity Distribution Annual Report for 2010-11, Tech. Rep. March (2012).

[56] World Resource Institute, The Time Value of Carbon and Carbon Storage, Tech. rep. (2010).

[57] C. Yuan, E. Wang, Q. Zhai, F. Yang, Temporal discounting in life cycle assessment: A critical review and theoretical framework Environmental Impact Assessment Review 51 (2015) 23-31. doi:10.1016/j.eiar.2015.01.001 URL linkinghub.elsevier.com/retrieve/pii/S0195925515000025

[58] J. Reap, F. Roman, S. Duncan, B. Bras, A survey of unresolved problems in life cycle assessment Part 1: goals and scope inventory analysis The International Journal of Life Cycle Assessment 13 (4) (2008) 290-300. doi : 10.1007/s11367-008-0008-x URL link.springer.com/10.1007/s11367-008-0008-x

[59] Department of Energy and Climate Change, 2013 UK Greenhouse Gas Emissions , Provisional Figures and 2012 UK Greenhouse Gas 
Emissions, Final Figures by Fuel Type and End-User Statistical release, Tech. Rep. March (2014).

[60] National Grid, A RIIO-T1 Stakeholder Consultation Tool: An Electricity Scenario Illustrator Tech. rep. (2012).

URL www.nationalgrid.com/NR/rdonlyres/9B3F9DAB-C02E-4A0D-9209-1941987B994E/56840/RIIOStakeholderConsultationv2CompatililityMode. pdfLastAccessed9/5/2016

[61] Electricity North West, Well Justified Business Plan 2015-2023, Tech. rep. (2014). 